\title{
Effects of vacuum-assisted closure and Drotrecogin alpha on inflammatory markers in severe acute pancreatitis
}

\author{
Oscar Arias-Carvajal ${ }^{1}$, José Manuel Hermosillo-Sandoval ${ }^{2}$, Carlos Alberto Gutiérrez-Martínez ${ }^{3}$, \\ Fermín Paul Pacheco-Moisés ${ }^{4}$, Genaro Gabriel Ortiz ${ }^{5}$, Adolfo Daniel Rodríguez-Carrizalez ${ }^{1}$, \\ Luis Miguel Román-Pintos ${ }^{1}$, Alejandra Guillermina Miranda-Díaz ${ }^{1 \#}$
}

\footnotetext{
${ }^{1}$ Department of Physiology, University Health Sciences Centre, University of Guadalajara, Guadalajara, México

${ }^{2}$ Department of General Surgery, Specialties Hospital, National Occidental Medical Centre, Social Security Institute of México, Guadalajara, México

${ }^{3}$ Intensive Care Unit, Specialties Hospital, National Occidental Medical Centre, Social Security Institute of México, Guadalajara, México

${ }^{4}$ Department of Chemistry, University of Guadalajara, Guadalajara, México

${ }^{5}$ Occidental Biomedical Research Centre, Social Security Institute of México, Guadalajara, México

Email: "
}

Received 15 May 2013; revised 16 June 2013; accepted 1 July 2013

Copyright (C) 2013 Oscar Arias-Carvajal et al. This is an open access article distributed under the Creative Commons Attribution License, which permits unrestricted use, distribution, and reproduction in any medium, provided the original work is properly cited.

\begin{abstract}
In severe acute pancreatitis (SAP) inflammatory processes foster necrosis, cellular lysis and liberation of vasoactive substances associated with multiple organ failure. The effects of vacuum-assisted closure and Drotrecogin alpha on inflammatory cytokines were evaluated in SAP patients with infected necrosis. Methods: Forty-six patients were included in three groups: Group 1, necrosectomy and abdominal cavity washing; Group 2, necrosectomy plus vacuum-assisted closure (VAC), and Group 3, necrossectomy plus VAC plus Drotrecogin alpha. Immunoreactive IL-32, TNF- $\alpha$, IL-6, TGF- $\beta$ and IL-2 cytokines were quantified with ELISA method. Results: IL-32 was significantly increased in all patients, predominantly the non-survivor of Group $3(p<0.0001)$. Group 2 maintained increased IL-32 levels throughout. Peak TNF- $\alpha$ was observed in non-survivors of Groups 1 and 2, with a frank tendency to decrease in Group 3. The IL-6 was increased, sustained throughout the study, peaking at the onset in non-survivors. At the end IL-6 tended to diminish, predominantly in survivors. TNF- $\alpha$ and IL-6 were significantly increased on hospitalization, with a maximum peak in non-survivors of all groups. Initial values of TGF- $\beta$ were significantly increased in survivors of the three groups, and were significantly diminished in non-survivors; affecting pancreas regeneration and favoring sys-

*Legal declaration: The authors claim sole responsibility for the information provided in this original study.

\#Corresponding author.
\end{abstract}

temic inflammation, with possible multiple-organ repercussions. IL-2 levels were elevated, predominantly in non-survivors of Group 1 . There was positive correlation between the increase IL-32 and TNF- $\alpha$, and negative correlation between the increase in TNF- $\alpha$ and decrease in TGF- $\beta$; and, a tendency for negative correlation between the IL-2 increased and TGF- $\beta$ levels. Conclusion: We found a generalized, sustained inflammatory state that fosters a torpid outcome in SAP patients.

Keywords: Severe Acute Pancreatitis; Systemic Inflammation; Proinflammatory Cytokines

\section{INTRODUCTION}

Acute pancreatitis (AP) is most frequently mild and selflimited ( $20 \%$ of cases) with spontaneous recovery. Severe acute pancreatitis (SAP) has a high morbidity and $20 \%-30 \%$ mortality rate [1]. SAP produces necrosis and cellular lysis with liberation of toxic, vasoactive substances that cause serious local and systemic lesions, associated with organ failure and/or complications that put patients' lives at risk [2]. The systemic inflammation typical of AP is identified by the increased levels of diverse proinflammatory cytokines [3]. Interleukin-32 (IL32) was originally identified as natural killer (NK) transcript 4 , which is induced by IL-18 in NK cells that play a critical role in inflammation. This cytokine is produced by NK, $\mathrm{T}$ and epithelial cells, monocytes and fibroblasts, after stimulation by IL-2, IL-12, IL-18 and interferon 
gamma [4]. The tumor necrosis factor alpha (TNF- $\alpha$ ) is a pleiotropic cytokine predominantly derived from macrophages, which plays an important role mediating many pathophysiological responses in sepsis, or excessive endocrine activation of pancreatic enzymes during SAP [5]. The TNF- $\alpha$ promotes expression of adhesion molecules by the endothelial cells and its activity is incremented in serious, systemic, inflammatory illnesses [6]. It is known that overproduction of IL-6 is considered a mortality or poor prognosis marker in patients with SAP [7]. Transforming growth factor beta (TGF- $\beta$ ) is implicated in pancreatic tissue repair but its role in SAP is not completely known. TGF- $\beta 1$ is involved in immune and inflammatory responses, and cell growth and differentiation. It plays an important role in pancreatic repair after AP and promotes the development of pancreatic fibrosis after repeated courses of induced AP because it regulates the remodeling of extracellular matrix during regeneration, and regulates the function of neutrophils. Infiltration of pancreatic neutrophils may be responsible, in part, for acinar cell necrosis [8]. IL-2 plays an anti-inflammatory role during SAP pathogenesis by attempting to compensate for inflammatory cytokine imbalance [9].

The early prediction of SAP continues to be difficult in clinical practice. Ranson's criteria are useful 48 hours after hospitalization, and evaluation of the acute and chronic pathophysiology (APACHE) II is only useful a few hours after the patient is hospitalized [10]. Since there have been no reports on the grade of structural damage of the pancreas and the clinical manifestations of the illness, no predictive system has been reported as ideal and no biochemical marker specific for the severity of AP is actually available; hence, we proposed the objective of evaluating the effects of vacuum-assisted closure (VAC) and Drotrecogin alpha on the inflammatory markers in SAP.

\section{PATIENTS AND METHODS}

When SAP is characterized by infected pancreatic necrosis, patients are necessarily subjected to percutaneous drainage; although, this treatment strategy is not always successful, the application of other management alternatives is recommended. Minimally invasive necrosectomy has recently come up as an attractive alternative that seems to give satisfactory results [11], and in the case of resulting insufficient, the patient is subjected to open or hand-assisted necrosectomy, which is associated with higher morbidity and mortality [12].

In a prospective cohort, from February 2009-June 2011, 46 patients who were hospitalized in Intensive Care Unit (ICU) and diagnosed with SAP, presenting with infected pancreatic necrosis diagnosed by percutaneous puncture and APACHE II $>8$, were included. The patients did not respond to systemic, integral management (parenteral solutions, amines, percutaneous drainage and enteral or early parenteral nutrition, depending on the individual characteristics of each patient), and they were subjected to open or hand-assisted surgical intervention at the General Surgery Service of the Specialties Hospital of the National Occidental Medical Centre of the Mexican Social Security Institute, as a reference hospital for gravely ill patients. Three study groups were formed, and 46 healthy volunteers of similar ages and genders were also included as a healthy control group.

Group 1: 16 patients with infected pancreatic necrosis, diagnosed by percutaneous drainage and poor response to conservative management, underwent necrosectomy and abdominal cavity washings every 48 hours.

Group 2: 24 patients with infected pancreatic necrosis, diagnosed by percutaneous drainage and managed conservatively for an average of 8 days, were subjected to open or hand-assisted necrosectomy and abdominal cavity washings plus VAC, applied every $48 \mathrm{~h}$.

The VAC system consisted in a biocompatible material in abdominal cavity (polyurethane sponge with permeable, adherent plastic film and impermeable plastic for a hermetic seal) connected to a sub-atmospheric suction pump (between $50-150 \mathrm{mmHg}$ ), continuous or intermitent, to provide continuous cleansing to the involved area and accelerate the healing process [13]. Application of the VAC system depended on the surgeon preference.

Group 3: 6 patients were subjected to necrosectomy for infected pancreatitis diagnosed by percutaneous puncture and presenting with inadequate response to conservative management. Patients underwent to abdominal cavity washings every $48 \mathrm{~h}$, plus VAC system plus Drotrecogin alpha (recombinant human activated protein C). They were identified by APACHE II $\geq 20$ on inclusion in the protocol, without particular affects to their coagulation times. Activated Drotrecogin (D) alpha is a glycoprotein analog of the endogenous human protein $\mathrm{C}$, produced by recombinant DNA technology; with $55 \mathrm{kDa}$ molecular weight that has anti-thrombotic, anti-inflammatory and pro-fibrinolytic properties, capable of reducing mortality in severe sepsis and in SAP [14,15]. The plasma clearance of the medication is $28 \pm 9 \mathrm{~L} / \mathrm{h}$, biphasic elimination kinetics (rapid phase of 13 minutes and slow of $1.6 \mathrm{~h}$ ). The infusion was $12-30 \mu \mathrm{g} / \mathrm{kg} / \mathrm{h}$ with stable plasma concentrations $2 \mathrm{~h}$ after initiation of the infusion. The mechanism by which Drotrecogin alpha improves survival in patients with sepsis has not been fully determined.

\subsection{Clinical Manifestations and Laboratory Assessment}

Inclusion criteria: patients with SAP, and infected necrosis, with APACHE II $>8$, and follow-up carried out on 
hospital admittance and discharge [16]. While the reported limit of its usefulness is up to $48 \mathrm{~h}$ after admittance, it was considered appropriate to measure until hospital discharge. Amylase, lipase, aspartate aminotransferase (AST), alanine aminotransferase (ALT), albumin, total and direct bilirubin, hemoglobin, hematocrit, leukocytes, glucose, calcium, potassium, sodium, creatinine, partial thromboplastin time and prothrombin time, were measured. Surgical interventions, length of ICU and total hospital stay, complications, and death when applicable were also determined.

\subsection{Blood Samples}

Blood samples were obtained by venipuncture immediately before the onset of anaesthesia for the first necrosectomy, with a sample taken every $48 \mathrm{~h}$; and the last was taken just prior to discharge, regardless of their destination (due to the large quantity of samples, those considered for the study were the initial baseline and final). Two vials were collected (10 $\mathrm{mL}$ each), one containing $0.1 \%$ of ethylene-diamine-tetra-acetic acid (EDTA), and other dry. Plasma and serum were separated by centrifugation at $3000 \mathrm{rpm}$ for $10 \mathrm{~min}$ at room temperature and stored at $-80^{\circ} \mathrm{C}$ until use.

\subsection{Inflammatory Cytokines}

The SAP is associated with systemic inflammatory response syndrome, and concentrations of tumor necrosis factor-alpha (TNF- $\alpha$ ), interleukin-32 (IL-32), interleukin6 (IL-6); transforming grow factor betal (TGF- $\beta 1$ ), and interleukin-2 (IL-2) were measured. These cytokines were evaluated in order to discern between the possibilities of survival/death throughout the course of the disease. Measurement of immunoreactive cytokines in the plasma was carried out by solid phase immune-absorbent assay with the multiple sandwich principle (ELISA). An eight-point pattern curve was prepared and optical density was read at $450 \mathrm{~nm}$. Results are expressed in $\mathrm{pg} / \mathrm{mL}$ and $\mathrm{ng} / \mathrm{L}$.

\subsection{Human TNF- $\alpha$, IL-6, TGF- $\beta 1$ and IL-2}

Kits were used following the manufacturer's specifications (R\&D Systems ${ }^{\circledR}$ USA). Monoclonal antibodies specific for TNF- $\alpha$, IL-6, TGF- $\beta 1$ and IL-2 were precoated onto microplates. Standards and samples were pipetted into the wells and any TNF- $\alpha$, IL-6, TGF- $\beta 1$ and IL-2 present were bound by the immobilized antibody. After washing away any unbound substances, an enzyme-linked polyclonal antibody specific for TNF- $\alpha$, IL-6, TGF- $\beta 1$ and IL-2 was added to the wells. Following a wash to remove any unbound antibody-enzyme reagent, a substrate solution was added to the wells and color developed in proportion to the amount of TNF- $\alpha$, IL-6,
TGF- $\beta 1$ and IL- 2 bound in the initial step. The color development was stopped and the intensity of the color was measured.

The IL-32 was established using ELISA kits (My Biosource ${ }^{\circledR}$ USA), following the manufacturers protocol. IL-32 ELISA is based on the biotin double antibody sandwich technique to assay human IL-32; which isadded to the wells, pre-coated with IL-32 monoclonal antibody, and then incubated. Afterwards, anti-IL-32 antibodies labeled with biotin, to unite with streptavidinHRP formingan immune complex. Unbound enzymes are removed after incubation and washing; and substrate A and $\mathrm{B}$ are added. The solution will turn blue and change to yellow with the effects of the acid. The intensity of the color is measured at $450 \mathrm{~nm}$ optical density.

\subsection{Ethical Considerations}

The local Research and Ethics Committee with registration number R-2009-1301-86 approved the study. Encrypted identification codes were assigned to assure patient confidentiality; and the study was performed in accordance with international and national laws, and taking into consideration all principles described in the Declaration of Helsinki, updated in the year 2000 in Edinburg, Scotland. Patients or relatives signed informed consents prior to participation.

\subsection{Statistical Analysis}

The statistical analysis was performed with SPSS. Quantitative data were expressed as mean $\pm \mathrm{SD}$, and qualitative variables were expressed as frequencies and percentages. Data did not follow a normal distribution (Shapiro-Wilk test), and comparisons were analyzed using the Mann-Whitney $U$ test between groups, for continuous variables. A two tailed value of $p<0.05$ was considered significant.

\section{RESULTS}

Table 1 demonstrates the general characteristics and demographics of the study groups. Patients treated with necrosectomy had the highest $(62.5 \%)$ mortality, and those treated with necrosectomy plus VAC plus Drotrecogin alpha had the lowest $(16.6 \%)$, despite the severity of their AP. The mortality of patients treated with necrosectomy plus VAC was 29\%. Patients treated with necrosectomy plus VAC and necrosectomy plus VAC plus Drotrecogin alpha were younger, which could have influenced their survival; although, there was an increase in the number of days spent in ICU and number of days hospitalized. The group treated with necrosectomy plus VAC plus Drotrecogin alpha had the highest value of APACHE II (24), however on hospitalization that diminished to 17 at discharge. The complications that emerged 


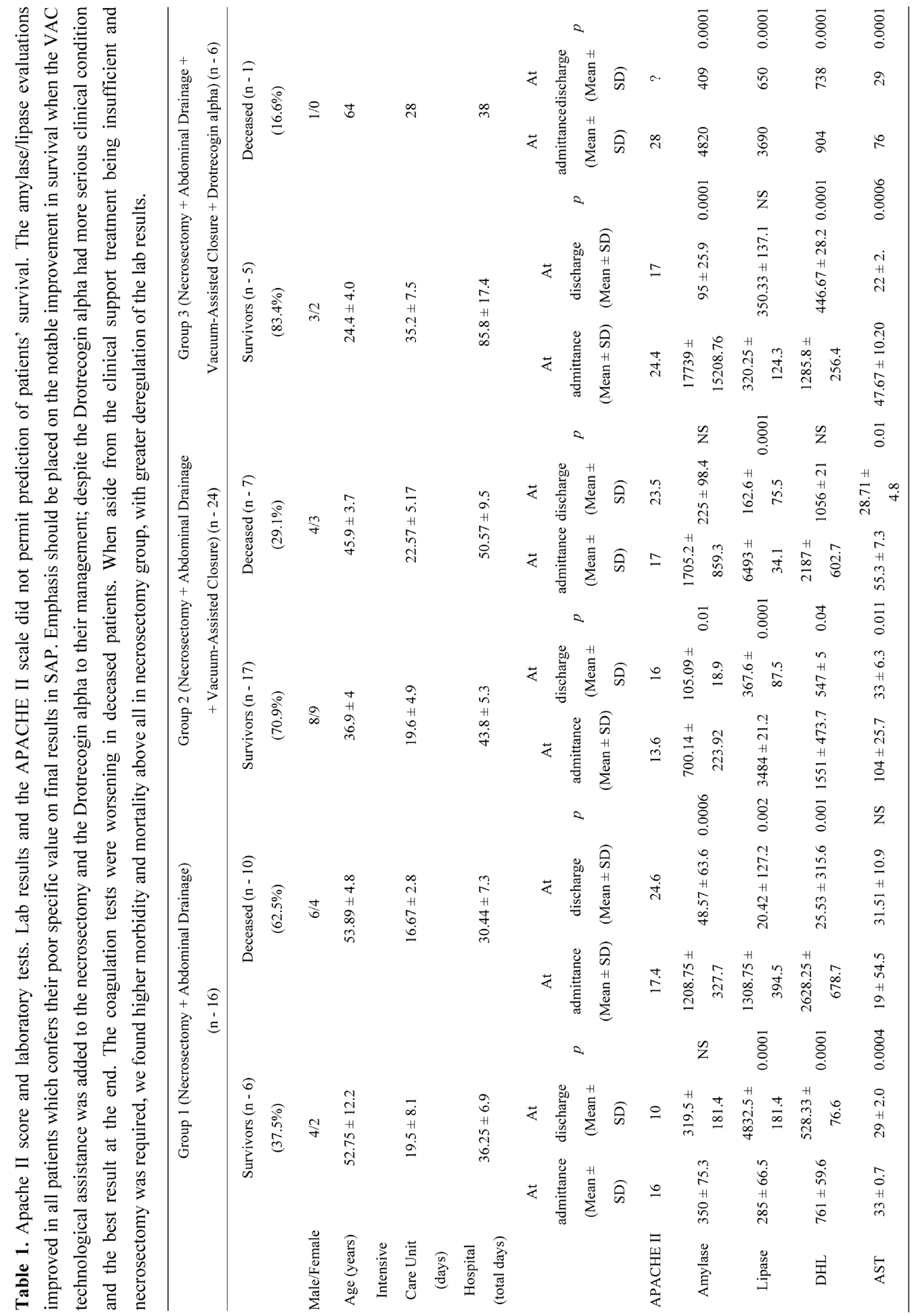




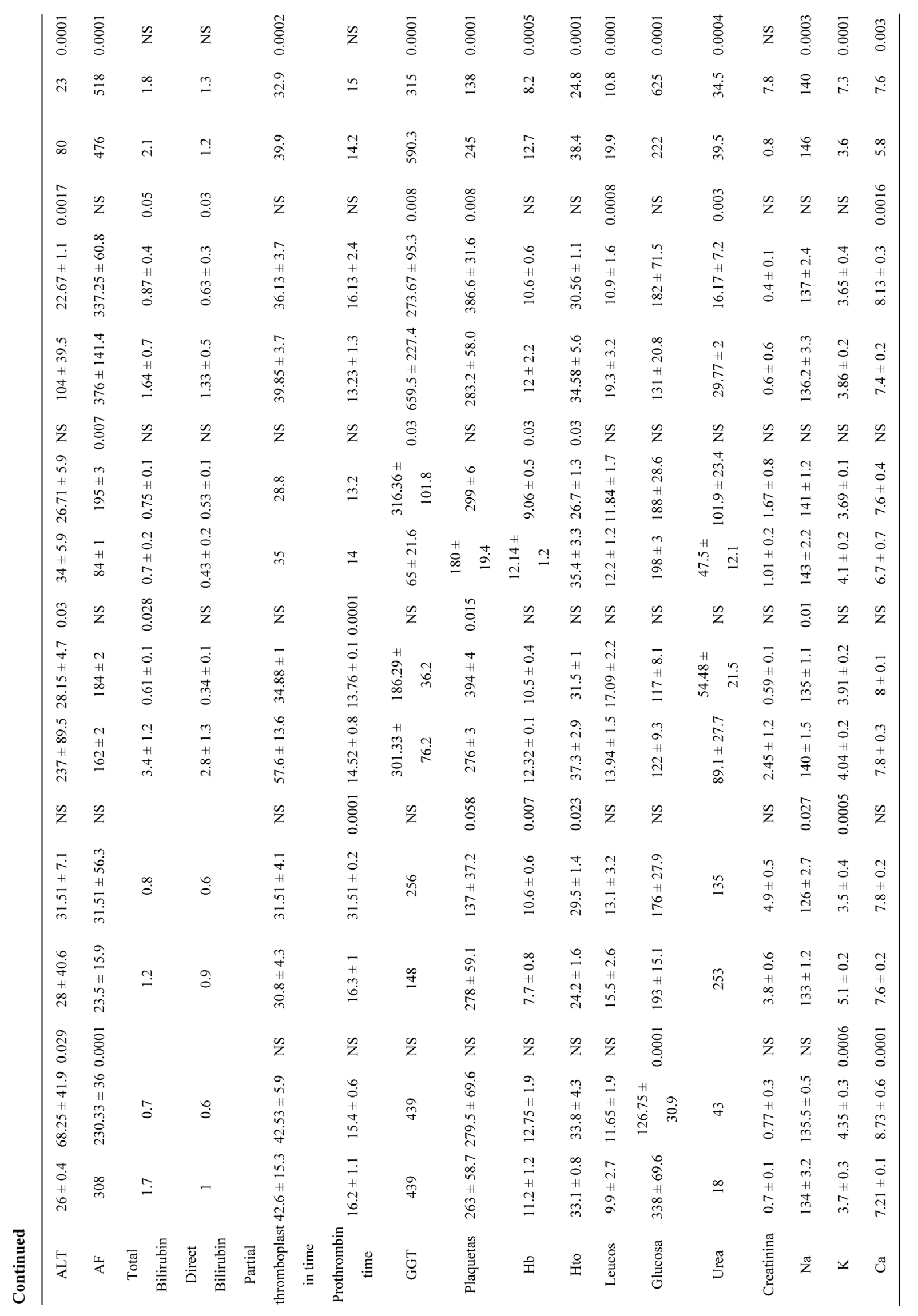


in this study were: sepsis, abdominal abscesses, kidney failure, acute respiratory failure, gastro-intestinal bleeding and thrombocytopenia. The pancreatic enzymes (amylase and lipase) diminished significantly in all groups, demonstrating the unspecificity of those results on final outcomes. The hepatic enzymes were significantly, favorably modified in the majority of survivors. The prothrombin time worsened and platelets decreased in nonsurvivors. The $\mathrm{Hb}$ and $\mathrm{Ht}$ decreased and glucose, urea and creatinine increased in non-survivors at the end of the study. Electrolytes tended to improve in all groups. As expected, serum $\mathrm{Ca}^{+}$levels were importantly diminished in all groups on hospitalization and tended to improve at the end of the study.

\subsection{IL-32}

Levels considered normal in healthy volunteers were
$47.00 \pm 7.00 \mathrm{ng} / \mathrm{L}$. All of the measurements, in all patients included were significantly incremented throughout the study, suggesting the important inflammatory state of those included $(p<0.0001)$. Survivors managed with necrosectomy at the onset had $147.44 \pm 85.06 \mathrm{ng} / \mathrm{L}$ and increased to $215 \pm 124 \mathrm{ng} / \mathrm{L}$ at the end. In non-survivors levels rose even more and persisted until the end without change: $296.29 \pm 111.99 \mathrm{ng} / \mathrm{L}$ and $295.43 \pm$ $111.66 \mathrm{ng} / \mathrm{L}$, respectively. The higher level of IL-32 was found in patients subjected to necrosectomy plus VAC plus Drotrecogin alpha. Survivors, at onset and end, had similar levels with $455.60 \pm 203 \mathrm{ng} / \mathrm{L}$ and $434.8 \pm 194$ $\mathrm{ng} / \mathrm{L}$, respectively. The maximum peak was observed in deceased patient $725 \mathrm{ng} / \mathrm{L}$ at the onset and $693.77 \mathrm{ng} / \mathrm{L}$ at the end. We found positive correlation between TNF- $\alpha$ and the baseline IL-32 ( $p<0.016)$ (Figures 1(a) and 2(c)).

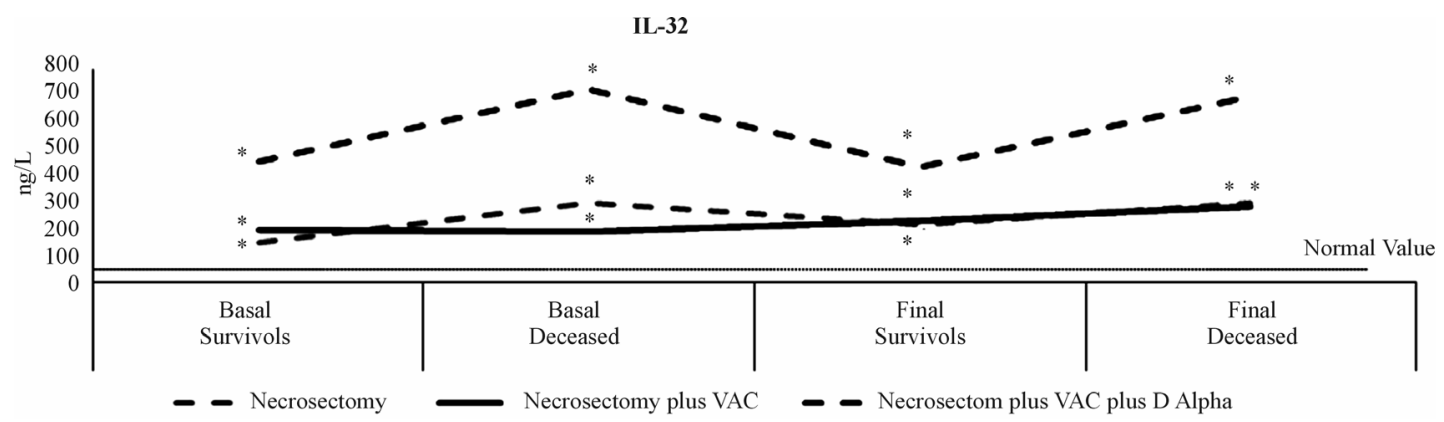

(a)

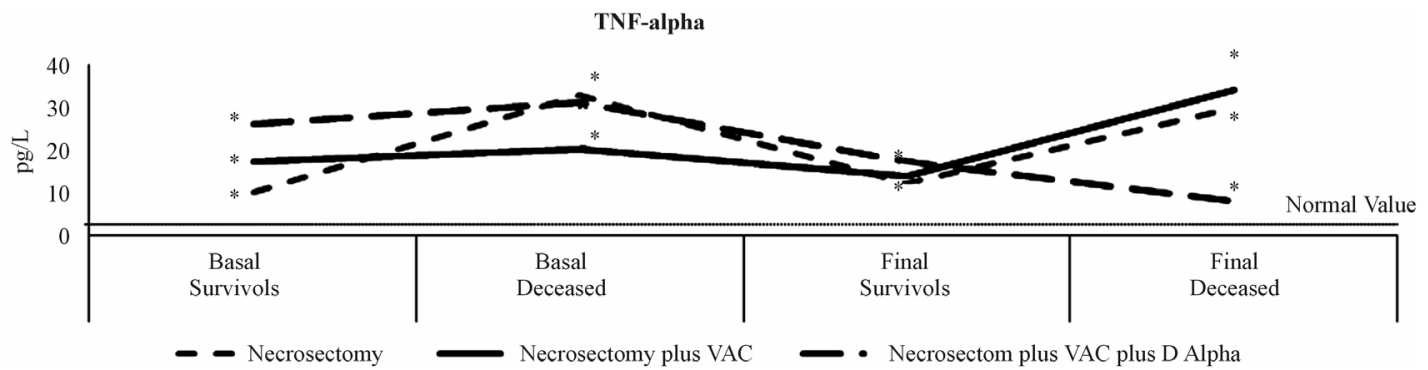

(b)

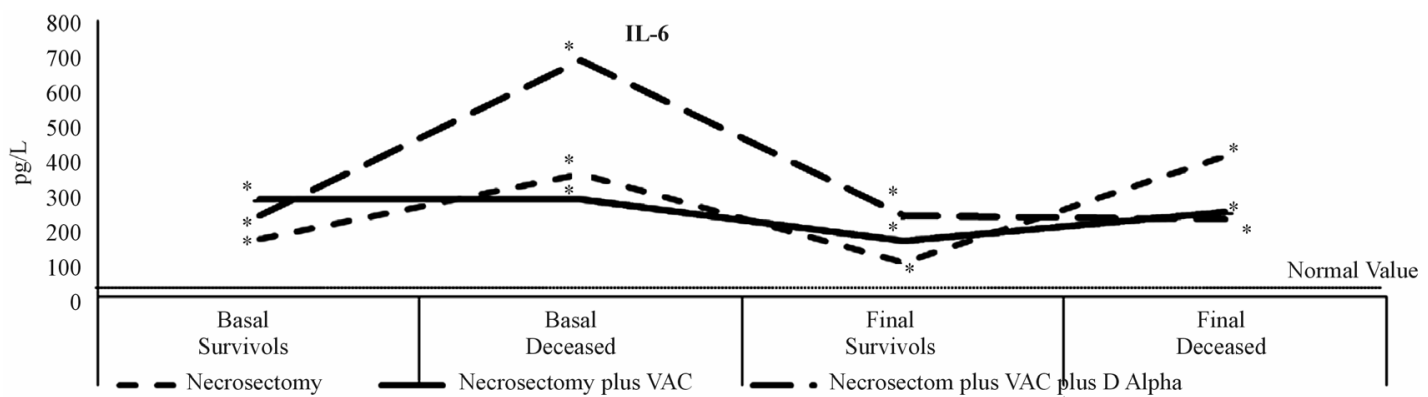

(c)

Figure 1. Inflammatory cytokines. A persistent inflammatory state was found in all three study groups with over-expression of IL-32 (1a), TNF- $\alpha$ (1b) and IL-6 (1c), predominantly in non-survivors since the beginning of the study until the final result. The poor results were found in no survivors. 


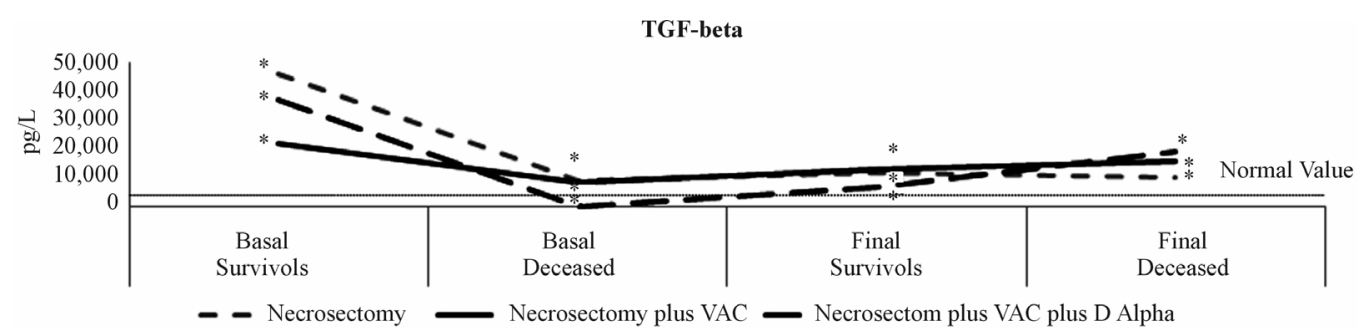

(a)

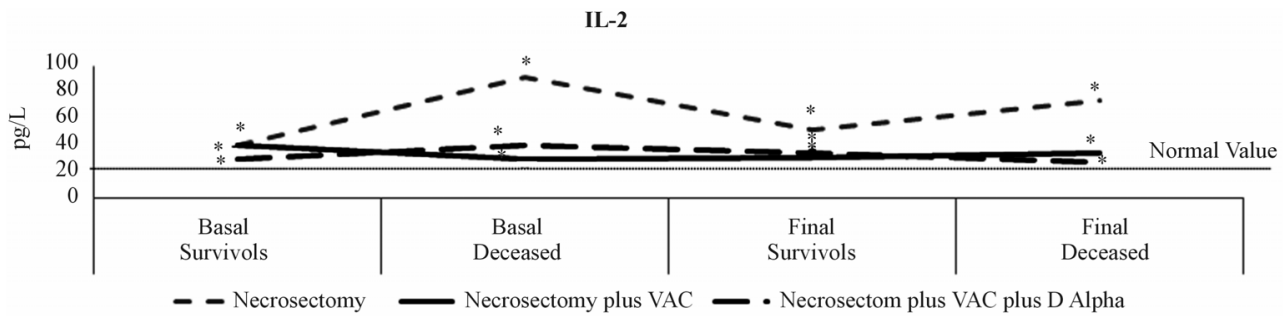

(b)

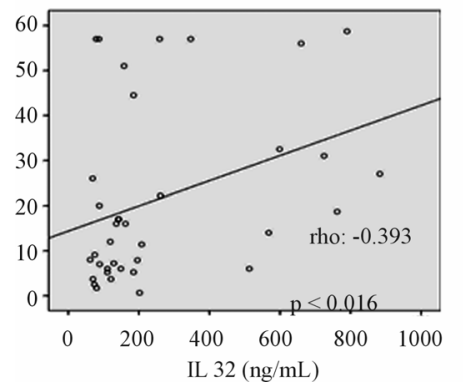

(c)

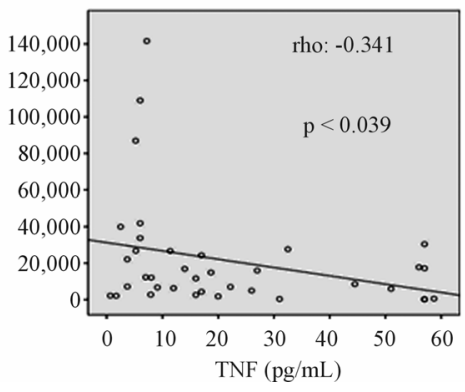

(d)

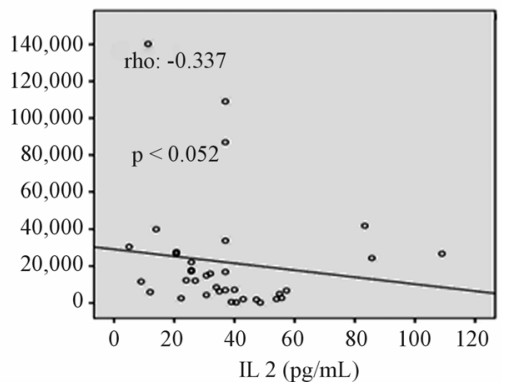

(e)

Figure 2. The behaviour of IL-2 and TGF- $\beta 1$. The IL-2 (2a) behaved as a sustained over-expression throughout the study in survivors of the three groups, and was even greater in non-survivors from the necrosectomy group; possibly trying to compensate for the severe inflammatory state or increased it as manifested by over-expression. Levels of TGF- $\beta 1$ (2b) were primarily over-expressed in survivors of the three groups; however, it was significantly lower in deceased patients, a situation that could have possibly influenced the fatal outcome of those patients. There was a positive correlation between high levels of IL-32 and TNF- $\alpha$ (2c), and negative correlation between increased levels of TNF- $\alpha$ and diminishedTGF- $\beta$ levels (2d); as well as a significant tendency between increased IL-2 levels and diminishedTGF- $\beta$ (2e), which demonstrates the important imbalance in the inflammatory markers in infected necrotizing SAP.

\subsection{TNF- $\alpha$}

TNF- $\alpha$ was not detected in healthy individuals. Baseline values in survivors of necrosectomy were $10.75 \pm 3.16$ $\mathrm{pg} / \mathrm{mL}$, and the final result $13.37 \pm 2.85 \mathrm{pg} / \mathrm{mL}$. The highest values were reported in non-survivors with 33.7 $\pm 5.96 \mathrm{pg} / \mathrm{mL}$ at study onset, and $30.96 \pm 5.91 \mathrm{pg} / \mathrm{mL}$ at the end $(p<0.0001)$. Survivors who underwent necrosectomy plus VAC had $17.90 \pm 4.84 \mathrm{pg} / \mathrm{mL}$ at onset, and $14.48 \pm 2.45 \mathrm{pg} / \mathrm{mL}$ at the end; vs. baseline values in non-survivors $20.21 \pm 5.59 \mathrm{pg} / \mathrm{mL}$, and an important increase $34.30 \pm 9.90 \mathrm{pg} / \mathrm{mL}$ at the end $(p<0.007)$. The initial values in the survivors of necrosectomy plus VAC plus Drotrecogin alpha decreased from $26.30 \pm 9.29$ to $17.15 \pm 4.57 \mathrm{pg} / \mathrm{mL}$ at the end; vs. the initial value in the deceased patient $31 \mathrm{pg} / \mathrm{mL}$, and $8.31 \mathrm{pg} / \mathrm{mL}$ at the end. These results suggest that all patients with SAP were found a continuous inflammatory state throughout the study, which tended to diminish in survivors when the SAP improved. In contrast, the expression tended to increase in non-survivors. The over expression of TNF- $\alpha$ in SAP was predictable from the onset, persisting throughout the study and predominating in those who experienced fatal conclusions; which, can be translated as the importance of the involvement of the Th1 cytokines in SAP (Figure 1(b)).

\subsection{IL-6}

The IL-6 is a pro-inflammatory cytokine produced in response to stimuli such as the over-expression of TNF- $\alpha$. The normal value of IL- 6 was $3.03 \pm 0.81 \mathrm{pg} / \mathrm{mL}$ with over-expression in the study groups from the onset until the end of follow-up. Levels of IL-6 in survivors tended to decrease at the end of the study; however, the initial serum levels in non-survivors were significantly increa- 
sed, mostly in patients who underwent necrosectomy and those subjected to necrosectomy plus VAC plus Drotrecogin alpha $(p<0.0001)$; although the difference between them was not significant in the final results, as shown in Figure 1(c), despite the maximum increase that was expected within the first $24-48 \mathrm{~h}$.

\subsection{TGF- $\beta 1$}

The TGF- $\beta 1$ is a potent, pro-inflammatory and pro-fibrogenic cytokine with an important role in cellular differentiation, growth and apoptosis. The normal value was $3778 \pm 1222 \mathrm{pg} / \mathrm{mL}$. The initial serum levels in survivors was significantly increased: $45928.58 \pm 16399.10 \mathrm{pg} / \mathrm{mL}$ (necrosectomy), $22150.58 \pm 8152.34 \mathrm{pg} / \mathrm{mL}$ (necrosectomy plus VAC), and $37153.45 \pm 18626.70 \mathrm{pg} / \mathrm{mL}$ (necrosectomy plus VAC and Drotrecogin alpha); and, at the end diminished significantly: $11773.88 \pm 4003.15$ $\mathrm{pg} / \mathrm{mL}$ (necrosectomy, $p<0.007$ ), $12805.22 \pm 2849.30$ $\mathrm{pg} / \mathrm{mL}$ (necrosectomy plus VAC, $p<0.0001$ ), and $6885.34 \pm 2492.79 \mathrm{pg} / \mathrm{mL}$ (necrosectomy plus VAC plus Drotrecogin alpha, $p<0.02$ ). Interestingly, the initial values in non-survivors were significantly lower compared to survivors: $8975.23 \pm 3183.15$ (necrosectomy), $8873.25 \pm 1982.81$ (necrosectomy plus VAC) and 330.50 $\mathrm{pg} / \mathrm{mL}$ (necrosectomy plus VAC plus Drotrecogin alpha). There was atendency for increased expression at the end of the study, prior to death: 10,079.12 $\pm 2878.72 \mathrm{pg} / \mathrm{mL}$ (necrosectomy), $15857.66 \pm 4545.36 \mathrm{pg} / \mathrm{mL}$ (necrosectomy plus VAC, $p<0.003$ ) and $19290.50 \mathrm{pg} / \mathrm{mL}$ (necrosectomy plus VAC plus Drotrecogin alpha). The over-expression of TGF- $\beta 1$ could be considered characteristic of SAP; however, were the expression significantly diminished it could have negative repercussions on recovery; preventing pancreas regeneration and affecting multiple organs and systems (Figure 1(d)). There was negative correlation between the TNF- $\alpha$ and baseline TGF- $\beta(p<0.039)$ (Figure 2(d)).

\subsection{IL-2}

Figure 1(e) shows IL-2 results. The IL-2 is considered a predominant anti-inflammatory. Normal serum levels were $28.36 \pm 4.95 \mathrm{pg} / \mathrm{mL}$, with over-expression at the onset in survivors of necrosectomy $40.67 \pm 7.33 \mathrm{pg} / \mathrm{mL}$, and $52.69 \pm 6.46 \mathrm{pg} / \mathrm{mL}$ at the end $(p<0.013)$; necrosectomy plus VAC had $41.3 \pm 8.2 \mathrm{pg} / \mathrm{mL}$ at the onset, and $31.7 \pm 3.6 \mathrm{pg} / \mathrm{mL}$ at the end $(p<0.004)$; however, in the group with necrosectomy plus VAC plus Drotrecogin alpha, the initial and final expressions were not significantly different, $30.21 \pm 8.40 \mathrm{pg} / \mathrm{mL}$ vs. $35.98 \pm 6.98$ $\mathrm{pg} / \mathrm{mL}$, respectively. On the other hand, there was a significant increase in baseline serum levels in non-survivors of the necrosectomy group vs. normal levels; possibly in an attempt to compensate for the severe inflamma- tory state in those patients: $92.63 \pm 26.91 \mathrm{pg} / \mathrm{mL}(p<$ $0.0004)$ that remained increased until the end $74.87 \pm$ 24.82. This cytokine behaved more evenly in the other managed groups, without significant differences between survivors and non-survivors. There was a tendency for negative correlation between the IL- 2 and baseline TGF$\beta(p<0.052)$ (Figure 2(e)).

\section{DISCUSSION}

The AP initiates with the insult, followed by auto-digestion of the pancreatic and extrapancreatic tissue. Inflammatory cells are recruited to the pancreas inducing the inflammatory cascade, with the capacity to produce local and systemic sequelae that can lead to multiple organ failure. Little is known of the relationship that exists between the clinical course of AP and the dynamic of the principal cytokines in the circulatory system, in presence or absence of complications to distant organs. Inflammatory factors involved in the genesis and progression of AP are dedicated to a fundamental role in the progression of the presentation, from mild to severe [17]. We evaluated the relationship between systemic mediators, on admission and hospital discharge, in patients with SAP, in a prospective cohort. SAP is associated to a significant, high morbidity and mortality rate; which, based on the lab results obtained on the APACHE II scale, we found were unable to predict results of the illness. We found significant deregulation on the increase of the inflammatory cytokines, with exception of TGF- $\beta 1$, which was found in abnormally low levels mostly affecting non-survivors.

The IL-32 is a recently described, pro-inflammatory cytokine characterized as favoring the activation of the nuclear factor (NF)-kB. The pancreatic ducts cells are a local source of IL-32; thus, it was feasible to find increased levels of IL-32 owing to the important role this cytokine plays in the inflammatory response [18], a situation that was found in the present study. Since IL-32 is a multi-functional cytokine it is capable of regulating cellular functions as important as inducing cellular differentiation and apoptosis [19]. TNF- $\alpha$ is secreted by monocytes, macrophages, neutrophils and $\mathrm{T}$ cells. In the present study, levels of TNF- $\alpha$ were significantly increased from the onset and remained elevated throughout the study, with maximum peak in non-survivors of all three groups. Similar results have been reported in the literature [20-22]. The IL-6 is the greatest mediator of acute phase reaction proteins since the pro-inflammatory mediators are produced in predictable sequence, initiated by the local liberation of IL- $1 \alpha$ and IL- 6 inducing the systemic inflammatory response, fostering inflammatory infiltration to organs distant from the pancreas, and producing multi-organ failure with capacity to cause death [23]. We found persistent, significantly elevated serum 
levels of IL-6 throughout hospitalization in the three study groups, with maximum expression in non-survivors from patients managed with necrosectomy, and in those who also received VAC and Drotrecogin alpha. It's probable that high levels of IL-6 can unchain the progression from SAP to a systemic inflammatory response syndrome and multi-organ failure. We think it could be convenient to consider IL-6 as a serum biomarker for the severity of SAP. The TGF- $\beta 1$ plays a fundamental role in regulation of growth, differentiation, cellular immunosuppression, angiogenesis, the process of inflammation, tissue repair and the formation of extracellular matrix (ECM). Also, TGF- $\beta 1$ plays an important role in the stimulation of the synthesis and inhibition of collagen, and its most important function is the pathogenesis of disturbances associated with the process of fibrosis [24]. The resolution/healing in SAP is a process regulated by the equilibrium that should exist between TGF- $\beta 1$ and degradation of ECM. However, the important role that it plays in the resolution of SAP has been studied very little in clinical practice [25]. We found over-expression of TGF- $\beta 1$ on initial evaluations in the survivors and nonsurvivors (except the deceased patient managed with necrosectomy plus VAC plus Drotrecogin alpha), compared to normal values. This over-expression was significantly less in non-survivors, and this relevant finding could have influenced the lack of resolution of the SAP process and possibly influenced the fatal outcome in those patients. The causes of SAP vary in their etiology, but the development of the severity of the illness is related to the imbalance of the immune system due to deregulation of the helper T cells [26]. Diverse reports emphasize the essential, dual role of the IL-2 in the immuno-tolerance and immuno-memory, contributing to the adequate homeostasis of the organism [27]. Few clinical reports exist that describe the anti-inflammatory behavior of the IL-2 in SAP. We found an over-expression of IL-2 at the onset and end in survivors of the three groups, and it was even greater in non-surviving patients managed with necrosectomy, possibly in an attempt to compensate for the severity of the inflammatory state or in contribution of the inflammatory state, indicated by the over-expression of the IL- 6 , IL-32, TNF- $\alpha$. The pattern of activation of the local and systemic mediators in SAP suggests the activation of local and systemic lymphocytes, with the appearance of complications to distant organs, fostering multi-organ failure and potentially leads to death [23]. We consider that periodic detection of the pro-inflammatory cytokines could favor more exact identification of severity than the Ranson and APACHE II. Scrutiny in the development of SAP should bring about other, important aspects such as sepsis, since up to $50 \%$ can die as a consequence of bacterial translocation caused by the pathogenesis and progression of the infection; and pancreatic necrosis increases the risk for multi-organ failure $[28,29]$.

The importance of the pathophysiological relationship between the greater, inflammatory state that SAP patients - managed with necrosectomyevery $48 \mathrm{~h}$ - presented with, had an impact of higher mortality in patients included in this study (62.5\%), contrary to that which was reported in the literature where the mortality fluctuated between $7 \%-42 \%$ [30]. It would therefore seem that necrosectomy, although periodic and systematic, is insufficient to control the abdominal and systemic catastrophe that presents in SAP. Open or hand-assisted necrosectomy was performed due to the hemodynamic instability which presented on inflating the abdominal cavity for laparoscopic necrosectomy in patients with necrotizing, infected SAP. When the VAC management system and the Drotrecogin alpha were added, while their benefits have been primarily tried in septic processes, the mortality diminished considerably $(29.1 \%$ and $16.6 \%$ ). Certainly, it must be emphasized that subjects managed with VAC system plus necrosectomy were younger than those solely managed with necrosectomy, though age was not a decisive criterion for treating physicians to assign them to one group or another, however, the response to intervention, taking into account the final scores on APACHE II, was similar in both groups at the study onset in survivors but increased in non-survivors. Patients managed with necrosectomy plus VAC plus Drotrecogin alpha were the youngest but they had the highest APACHE II, and the lowest mortality. Although we cannot conclude that the combination of therapeutic resources (Necrosectomy, VAC, and Drotrecogin alpha) utilized in these patients is essential for decreasing mortality in SAP, it remains a pending assignment to investtigate this therapeutic combination in a greater number of patients with similar characteristics. The probability of predicting and developing severity in AP was reported in a model that involved PCR levels and some select parameters on the APACHE II scale, and that the use of the VAC system involves the combination of evaluation parameters that more precisely predict the severity of AP than with isolated variables like age [31]. Emphasis must be placed on the greater length of hospital and ICU stays in these patients because it importantly increases the costs of hospital and medical attention, even greater than that reported by Pérez, D. et al. [32], whose patients with abdominal sepsis reported an average ICU hospitalization of 20 days. Nonetheless, improved survival in the patients was achieved to $70.9 \%$ in those managed with VAC, and $83.4 \%$ in those who in addition received Drotrecogin alpha. The advantage of the VAC system is essentially based on its favoring the moistening of the exudate, rich in pro-inflammatory substances, despite the inflammatory state sustained in SAP. 
We found significant decrease in the IL-32, TNF- $\alpha$ and IL- 6 in survivors of the groups treated with necrosectomy plus VAC and necrosectomy plus VAC plus Drotrecogin alpha, contrary to the conventional group (Necrosectomy) where a significant increase in TNF- $\alpha$, IL-6 and deregulation of TGB- $\beta 1$ was found in non-survivors. These findings follow the tendency observed by Labler, L. et al. [33] who evaluated, in traumatic injuries, levels of growth factors and cytokines in the serum and at the wound sites of patients treated with VAC system, and they reported up to $65 \%$ decrease in IL-6 compared to baseline values.

We conclude that the inflammatory state generally observed and sustained in the present study resulted in less than favorable, torpid outcomes in patients with SAP. Technological advances such as early use of the VAC system, offer advantages in survival of patients who suffer from infected, necrotizing SAP; as well, management with Drotrecogin alpha in select patients provides advantages in the management of open or laparoscopicnecrosectomy.

\section{ACKNOWLEDGEMENTS}

M in Sc Rogelio Troyo Sanromán for the analytical support.

\section{REFERENCES}

[1] Kamer, E., Unalp, H.R., Derici, H., Tansug, T. and Onal, M.A. (2007) Early diagnosis and prediction of severity in acute pancreatitis using the urine trypsinogen-2 dipstick test: A prospective study. World Journal of Gastroenterology, 13, 6208-6212. doi:10.3748/wjg.13.6208

[2] Bollen, T.L., van Santvoort, H.C., Besselink, M.G., van Leeuwen, M.S., Horvath, K.D., Freeny, P.C., et al. (2008) The Atlanta Classification of acute pancreatitis revisited. British Journal of Surgery, 95, 6-21. doi: $10.1002 /$ bjs. 6010

[3] Aoun, E., Chen, J., Reighard, D., Gleeson, F.C., Whitcomb, D.C. and Papachristou, G.I. (2010) Diagnostic accuracy of interleukin-6 and interleukin- 8 in predicting severe acute pancreatitis: A meta-analysis. Pancreatology, 9, 777-785. doi:10.1159/000214191

[4] Kim, S.H., Han, S.Y., Azam, T., Yoon, D.Y. and Dinarello, C.A. (2005) Interleukin-32: A cytokine and inducer of TNF-alpha. Immunity, 22, 131-142.

[5] Dambrauskas, Z., Giese, N., Gulbinas, A., Giese, T., Berberat, P.O., Pundzius, J., et al. (2010) Different profiles of cytokine expression during mild and severe acute pancreatitis. World Journal of Gastroenterology, 16, 18451853. doi:10.3748/wig.v16.i15.1845

[6] Beutler, B. and Cerami, A. (1987) Cachectin: More than a tumor necrosis factor. The New England Journal of Medicine, 316, 379-385. doi:10.1056/NEJM198702123160705

[7] Zhang, H., Neuhöfer, P., Song, L., Rabe, B., Lesina, M., Kurkowski, M.U., et al. (2013) IL-6 trans-signaling pro- motes pancreatitis-associated lung injury and lethality. Journal of Clinical Investigation, 123, 1019-1031. doi:10.1172/JCI64931

[8] Sandoval, D., Gukovskaya, A., Reavy, P., et al. (1996) The role of neutrophils and platelet-Activating factor in mediating experimental pancreatitis. Gastroenterology, 111, 1081-1091.

[9] Kilciler, G., Musabak, U., Bagci, S., Yesilova, Z., Tuzun, A., Uygun, A., et al. (2008) Do the changes in the serum levels of IL-2, IL-4, TNFalpha, and IL-6 reflect the inflammatory activity in the patients with post-ERCP pancreatitis? Clinical and Developmental Immunology, 2008, 481560. doi: $10.1155 / 2008 / 481560$

[10] Lempinen, M., Stenman, U.H., Finne, P., Puolakkainen, P., Haapiainen, R., Kemppainen, E. (2003) Trypsinogen2 and trypsinogen activation peptide (TAP) in urine of patients with acute pancreatitis. Journal of Surgical Research, 111, 267-273. doi:10.1016/S0022-4804(03)00044-1

[11] Bucher, P., Pugin, F. and Morel, P. (2008) Minimally invasive necrosectomy for infected necrotizing pancreatitis. Pancreas, 36, 113-119. doi:10.1097/MPA.0b013e3181514c9e

[12] Besselink, M.G., van Santvoort, H.C., Boermeester, M.A., Nieuwenhuijs, V.B., van Goor, H., Dejong, C.H., et al. (2009) Timing and impact of infections in acutepancreatitis. British Journal of Surgery, 96, 267-273. doi:10.1002/bjs.6447

[13] Wondberg, D., Larusson, H.J., Metzger, U., Platz, A. and Zingg, U. (2008) Treatment of the open abdomen with the commercially available vacuum-assisted closure system in patients with abdominal sepsis. World Journal of Surgery, 32, 2724-2729. doi:10.1007/s00268-008-9762-y

[14] Jamdar, S. and Siriwardena, A.K. (2005) Drotrecoginalfa (recombinant human activated protein $\mathrm{C}$ ) in severe acute pancreatitis. Critical Care, 9, 321-322. doi:10.1186/cc3777

[15] Pettilä, V., Kyhälä, L., Kylänpää, M.L., Leppäniemi, A., Tallgren, M., Markkola, A., et al. (2010) APCAP-activatedprotein $\mathrm{C}$ in acutepancreatitis: A double-blind randomized human pilot trial. Critical Care, 14, R139. doi:10.1186/cc9203

[16] De Campos, T., Cerqueira, C., Kuryura, L., Parreira, J.G., Soldá, S., Perlingeiro, J.A., et al. (2008) Morbimortality indicators in severe acute pancreatitis. JOP, 9, 690-697.

[17] Cappell, M.S. (2008) Acute pancreatitis: Etiology, clinical presentation, diagnosis, and therapy. Medical Clinics of North America, 92, 889-923. doi:10.1016/j.mena.2008.04.013

[18] Nishida, A., Andoh, A., Inatomi, O. and Fujiyama, Y. (2009) Interleukin-32 expression in the pancreas. The Journal of Biological Chemistry, 284, 17868-17876. doi:10.1074/jbc.M900368200

[19] Heinhuis, B., Koenders, M.I., van den Berg, W.B., Netea, M.G., Dinarello, C.A. and Joosten, L.A. (2012) Interleukin 32 (IL-32) contains a typical $\alpha$-helix bundle structure that resembles focal adhesion targeting region of focal adhesion kinase-1. The Journal of Biological Chemistry, 287, 5733-5743. doi:10.1074/jbc.M111.288290 
[20] Panek, J., Karcz, D., Pieton, R., Zasada, J., Tusinski M., Dolecki, M., et al. (2006) Blood serum levels of proinflammatory cytokines in patients with different degrees of biliary pancreatitis. Canadian Journal of Gastroenterology, 20, 645-648.

[21] Zhang, H., Patel, S.A., Kandil, E., Mueller, C.M., Lin, Y.Y. and Zenilman, M.E. (2003)Pancreaticelastase is proven to be a mannose-binding protein-Implications for the systemicresponse to pancreatitis. Surgery, 133, 678688. doi: $10.1067 / \mathrm{msy} .2003 .175$

[22] Jaffray, C., Mendez, C., Denham, W., Carter, G. and Norman, J. (2000) Specific pancreatic enzymes activate macrophages to produce tumor necrosis factor-alpha: Role of nuclear factor kappa B and inhibitory kappa B proteins. Journal of Gastrointestinal Surgery, 4, 370-377. doi:10.1016/S1091-255X(00)80015-3

[23] Mayer, J., Rau, B., Gansauge, F. and Beger, H.G. (2000) Inflammatory mediators in human acutepancreatitis: Clinical and pathophysiological implications. Gut, 47, 546552. doi:10.1136/gut.47.4.546

[24] Friess, H., Lu, Z., Riesle, E., Uhl, W., Bründler, A.M., Horvath, L., et al. (1998) Enhanced expression of TGFbetas and their receptors in human acute pancreatitis. Annals of Surgery, 227, 95-104. doi:10.1097/00000658-199801000-00014

[25] Kihara, Y., Tashiro, M., Nakamura, H., Yamaguchi, T., Yoshikawa, H. and Otsuki, M. (2001) Role of TGF-beta1, extracellular matrix, and matrix metalloproteinase in the healing process of the pancreas after induction of acute necrotizing pancreatitis using arginine in rats. Pancreas, 23, 288-295. doi:10.1097/00006676-200110000-00010

[26] Zhang, X., Chez, H., Liu, F. and Zhang, J. (2009) Advances in researches on the immune dysregulation and therapy of severe acute pancreatitis. Journal of Zhejiang University Science B, 10, 493-498.
doi:10.1631/jzus.B0820265

[27] Malek, T.R. (2008) The biology of interleukin-2. Annual Review of Immunology, 26, 453-479. doi:10.1146/annurev.immunol.26.021607.090357

[28] Fritz, S., Hartwig, W., Lehmann, R., Will-Schweiger, K., Kommerell, M., Hackert, T., et al. (2008) Phrophylactic antibiotic treatment is superior to therapy on-demand in experimental necrotising pancreatitis. Critical Care, 12, R141. doi:10.1186/cc7118

[29] Heinrich, S., Schäfer, M., Rousson, V. and Clavien, P.A. (2006) Evidence-based treatment of acute pancreatitis. A look at established paradigms. Annals of Surgery, 243, 154-168. doi:10.1097/01.sla.0000197334.58374.70

[30] Wang, X., Cui, Z., Li, H., Saleen, A.F., Zhang, D., Miao, B., et al. (2010) Nosocomial mortality and early prediction of patients with severe acute pancreatitis. Journal of Gastroenterology and Hepatology, 25, 1386-1393. doi:10.1111/j.1440-1746.2010.06376.x

[31] Pearce, C.B., Gunn, S.R., Ahmed, A. and Johnson, C.D. (2006) Machine learning can improve prediction of severity in acute pancreatitis using admission values of APACHE II score and C-reactive protein. Pancreatology, 6, 123-131. doi:10.1159/000090032

[32] Perez, D., Wildi, S., Demartines, N., Bramkamp, M., Koehler, C. and Clavien, P.A. (2007) Prospective evaluation of vacuum-assisted closure in abdominal compartment syndrome and severe abdominal sepsis. Journal of the American College of Surgeons, 205, 586-592. doi:10.1016/j.jamcollsurg.2007.05.015

[33] Labler, L., Mica, L., Härter, L., Trentz, O. and Keel, M. (2006) Influence of VAC therapy on cytokines and growth factors in traumatic wounds. Zentralblatt für Chirurgie, 131, S62-S67. doi:10.1055/s-2006-921511 